\title{
Colonization of Tomato Seedlings by Bioluminescent Clavibacter michiganensis subsp. michiganensis Under Different Humidity Regimes
}

\author{
Xiulan Xu, Gireesh Rajashekara, Pierce A. Paul, and Sally A. Miller
}

First, third, and fourth authors: Department of Plant Pathology, and second author: Food and Animal Health Research Program, The Ohio State University, Ohio Agricultural Research and Development Center, Wooster 44691. Accepted for publication 13 September 2011.

\begin{abstract}
Xu, X., Rajashekara, G., Paul, P. A., and Miller, S. A. 2012. Colonization of tomato seedlings by bioluminescent Clavibacter michiganensis subsp. michiganensis under different humidity regimes. Phytopathology 102:177-184.

Tomato bacterial canker, caused by Clavibacter michiganensis subsp. michiganensis, is transmitted by infected or infested seed and mechanically from plant to plant. Wounds occurring during seedling production and crop maintenance facilitate the dissemination of the pathogen. However, the effects of environmental factors on C. michiganensis subsp. michiganensis translocation and growth as an endophyte have not been fully elucidated. A virulent, stable, constitutively bioluminescent $C$. michiganensis subsp. michiganensis strain BL-Cmm 17 coupled with an

in vivo imaging system allowed visualization of the $C$. michiganensis subsp. michiganensis colonization process in tomato seedlings in real time. The dynamics of bacterial infection in seedlings through wounds were compared under low $(45 \%)$ and high $(83 \%)$ relative humidity. Bacteria multiplied rapidly in cotyledon petioles remaining after clip inoculation and moved in the stem toward both root and shoot. Luminescent signals were also observed in tomato seedling roots over time, and root development was reduced in inoculated plants maintained under both humidity regimes. Wilting was more severe in seedlings under highhumidity regimes. A strong positive correlation between light intensity and bacterial population in planta suggests that bioluminescent $C$. michiganensis subsp. michiganensis strains will be useful in evaluating the efficacy of bactericides and host resistance.
\end{abstract}

Tomato bacterial canker, one of the most destructive diseases of tomato, causes serious economic losses worldwide $(15,35)$. The pathogen Clavibacter michiganensis subsp. michiganensis is a rod-shaped, gram-positive bacterium that belongs to the family Microbacteriaceae (27). Yield loss from tomato canker is due to plant wilting and death, reduced photosynthetic capacity, fruit lesions (field) or netting (greenhouse), and reduced fruit set and size. Severe epidemics can cause up to $80 \%$ yield loss $(26,35)$.

The pathogen $C$. michiganensis subsp. michiganensis is seedborne, and infected seed or transplants are considered to be the source of primary inoculum in a disease-free field or greenhouse $(6,16,35)$. The occurrence of tomato canker in a production greenhouse can be economically devastating due to the difficulty of eradication of the pathogen, additional cost of sanitation, and yield reduction. Economic loss caused by bacterial canker is as high as 25 to $30 \%$ in greenhouse tomato production nationally (M. Bledsoe, personal communication). The management of tomato bacterial canker is primarily dependent on maintaining pathogen-free seed and transplants. There are no commercial tomato cultivars highly resistant to canker, or effective foliar or root-applied bactericides available (21). Although tomato seed is routinely tested for $C$. michiganensis subsp. michiganensis and production of healthy transplants is an industry priority, epidemics of tomato canker continue to occur. For example, a severe field outbreak of tomato canker in the U.S. Midwest and Ontario in 1984 was initiated with certified transplants produced in

Corresponding author: S. A. Miller; E-mail address: miller.769@ osu.edu

* The $e$-Xtra logo stands for "electronic extra" and indicates that the online version contains a supplemental figure.

http://dx.doi.org/10.1094/PHYTO-03-11-0090

(C) 2012 The American Phytopathological Society
Georgia (16). Several outbreaks of bacterial canker in tomato propagation and production greenhouses in the United States, Canada, Mexico, and Guatemala in the last decade have caused serious losses (S. Miller, unpublished).

For both fresh-market and processing field-tomato production, seedlings are usually produced in a greenhouse for 4 to 6 weeks before transplanting. Seed infected with $C$. michiganensis subsp. michiganensis often give rise to symptomless seedlings, which may harbor latent infections or carry the pathogen epiphytically $(16,33,36)$. These asymptomatic seedlings may escape inspection and cause epidemics after transplanting. An early study showed that seedlings grown from artificially infested seed were contaminated with $10^{4}$ to $10^{8} \mathrm{CFU} /$ seedling (36). Seedlings grown from naturally infected seed can also carry $10^{3}$ to $10^{4} \mathrm{CFU} / \mathrm{g}$ of the pathogen in shoots (33). In greenhouse transplant production, because the density of seedlings is very high, epiphytic C. michiganensis subsp. michiganensis are easily spread through irrigation and leaf-to-leaf contact. It is known that $C$. michiganensis subsp. michiganensis is a good endophyte and moves into the xylem after its entrance through wounds or natural openings $(3,15)$. Mechanical wounds, which are easily made during grafting, clipping, harvesting, shipping, and transplanting, promote the dissemination of $C$. michiganensis subsp. michiganensis directly into vascular tissue (6).

In addition, environmental conditions in seedling production greenhouses favor bacterial survival and infection. It has been reported that optimum conditions for tomato bacterial canker symptom development are warm temperatures $\left(23\right.$ to $\left.28^{\circ} \mathrm{C}\right)$ and high relative humidity $(\mathrm{RH})(>80 \%)(2)$. Previous studies have focused on $C$. michiganensis subsp. michiganensis spread by cultural practices and the development of symptoms $(2,6,7)$; however, few studies have addressed $C$. michiganensis subsp. michiganensis movement in planta during latent infection and the 
influence of environmental conditions on C. michiganensis subsp. michiganensis growth as an endophyte in tomato transplants. RH is an important environmental factor in tomato seedling production because, under current practices, high RH is standard during seed germination and transplant production, particularly for grafted seedlings. High-RH conditions also persist during plant production in greenhouses, especially in winter in many northern climates. We speculated that systemic infection by $C$. michiganensis subsp. michiganensis develops rapidly in young tomato plants, within days after the pathogen is introduced via wounding, and that $C$. michiganensis subsp. michiganensis endophytic growth and translocation are influenced by humidity.

To facilitate monitoring of the dynamics of $C$. michiganensis subsp. michiganensis infection in tomato seedlings, we have constructed a bioluminescent $C$. michiganensis subsp. michiganensis strain, BL-Cmm17, by transformation of a lux-operon originally from Photorhabdus luminescens into the $C$. michiganensis subsp. michiganensis genome (38). The natural light-emitting reactions encoded by the luxCDABE genes have also been transferred to phytopathogenic Xanthomonas campestris pathovars and Pseudomonas spp. to track bacterial movement and distribution in host plants $(8,9,29,32)$, and to assess host susceptibility quantitatively (13). In particular, lux-marked Ralstonia solanacearum has been used to study bacterial translocation in single- or double-grafted tomato plants with combinations of resistant and susceptible cultivars (18).

In a previous study, we demonstrated the use of strain BLCmm17 to monitor $C$. michiganensis subsp. michiganensis colonization in germinating tomato seed in vivo (38). However, the movement of bioluminescent $C$. michiganensis subsp. michiganensis in grafted tomato seedlings was not imaged due to background light emission caused by plant phosphorescence. In this investigation, we have improved the approach by imaging plants that were incubated in the dark to quench the phosphorescence and have successfully monitored $C$. michiganensis subsp. michiganensis systemic infection of tomato seedlings under different humidity regimes in real time.

\section{MATERIALS AND METHODS}

Bacterial strain and growth conditions. Strain BL-Cmm17, which is virulent and constitutively bioluminescent and contains a stable insertion of the luxABCDE genes (38), was used in this study. BL-Cmm17 was cultured from glycerol stock maintained at $-80^{\circ} \mathrm{C}$. Bacteria were grown on nutrient broth-yeast extract (NBY) medium (37) containing chloramphenicol at $10 \mu \mathrm{g} / \mathrm{ml}$ at $28^{\circ} \mathrm{C}$.

Tomato seedling inoculation and incubation under different RH regimes. Tomato seed ('OH9242') were sown in Fafard superfine germination soil mix (Conrad Fafard Inc., Agawam, MA) in 50-well trays and maintained in the greenhouse. General fertilizer (Peters 20-20-20; J. R. Peters Inc., Allentown, PA) was applied weekly. Tomato seedlings were inoculated by clipping the cotyledons when plants were 4 weeks old. Cultures of BL$\mathrm{Cmm} 17$ were collected from NBY plates after incubation at $28^{\circ} \mathrm{C}$ for 4 days and suspended in sterilized water to an optical density at $600 \mathrm{~nm}$ of $0.25\left(\approx 3.6 \times 10^{8} \mathrm{CFU} / \mathrm{ml}\right)$. Petioles of both cotyledons were cut using a pair of sterilized dissecting scissors that had been dipped in the bacterial suspension. In total, 30 seedlings were inoculated with BL-Cmm17 and 30 seedlings were controls cut with scissors dipped in sterilized water. After cutting the cotyledons, all seedlings were placed in a growth chamber (Conviron Model EF7; Conviron, Manitoba, Canada) with high $\mathrm{RH}(80 \% \mathrm{RH})$ at $25^{\circ} \mathrm{C}$ for $6 \mathrm{~h}$. Half of the inoculated $(n=15)$ and control seedlings $(n=15)$ were then transferred to a low-humidity growth chamber. Both chambers were set up with a 12 -h photoperiod at 20 and $25^{\circ} \mathrm{C}$ in darkness and light, respectively. HOBO U14 LCD loggers (Onset Computer Corporation, Bourne, MA) placed in each growth chamber showed similar temperature data for both chambers, whereas the RH was $83 \pm$ $5 \%$ (high-RH chamber) and $45 \pm 12 \%$ (low-RH chambers). The larger deviation of $\mathrm{RH}$ in the low-RH growth chamber was due to daily watering.

Bioluminescent imaging of BL-Cmm17 colonization of tomato seedlings. Tomato seedlings were imaged to monitor the movement of bacteria 5, 10, 15, and 20 days postinoculation (DPI) using an in vivo imaging system (IVIS) (Xenogen Corporation, Alameda, CA). Tomato seedlings were placed in the lightproof imaging chamber with a sample stage temperature of $25^{\circ} \mathrm{C}$. Due to the high sensitivity of the IVIS thermoelectrically cooled charge-coupled device (CCD) camera, plant phosphorescence was detected immediately after the plants were placed in the image chamber. A preliminary study in which plants were placed in the dark on the sample stage and imaged with $3 \mathrm{~min}$ of exposure time every 5 min under dark incubation indicated that the background phosphorescence was quenched after $10 \mathrm{~min}$ in the dark. Therefore, all images were taken after $10 \mathrm{~min}$ of dark incubation. Images of individual leaves were taken 20 DPI. Tomato seedlings roots were also imaged every 5 DPI after sacrificing one randomly selected plant per replicate from each treatment. Tomato roots were gently washed in water to remove the attached soil and dried at room temperature for 5 min before taking bioluminescent images. Incubation in the dark was not necessary for roots, which lacked background phosphorescence. All images were saved and analyzed using the Living Image software (Xenogen Corporation) at a PC workstation. Total flux (photons per second) from the region $1 \mathrm{~cm}$ above the cotyledons (the tissue sampled for isolation) was measured using Living Image software to determine the relationship of light intensity to bioluminescent bacterial populations in stems. The experiment was repeated once.

Quantification of BL-Cmm17 in planta and imprinting of stem tissue. After each bioluminescent imaging (5, 10, 15, and 20 DPI), three seedlings were selected at random from low and high RH for $C$. michiganensis subsp. michiganensis enumeration. Three petioles were randomly sampled immediately after clipping and ground in a 1.2-ml library tube with $0.6 \mathrm{ml}$ of potassium phosphate buffer $(\mathrm{pH}=7.4,10 \mathrm{mM})$. Then, 10-fold serial dilutions of each sample were made and $0.1-\mathrm{ml}$ aliquots were plated on NBY containing chloramphenicol at $10 \mu \mathrm{g} / \mathrm{ml}$. Each tomato compound leaf was sampled separately using sterilized forceps, surface sterilized by spraying with $70 \%$ ethanol, and wiped with clean tissues. Stem samples were cut from the inoculation point to $1 \mathrm{~cm}$ above using a sterilized scalpel. Leaf and stem samples were weighed and ground in whirl-pack sample bags (VWR International LLC, West Chester, PA) with $3 \mathrm{ml}$ of potassium phosphate buffer using a roller/tissue homogenizer (Agdia Inc., Elkhart, IN). Root samples were taken for bacterial isolation after imaging as described above. Entire root systems were weighed and surface sterilized by dipping quickly in $70 \%$ ethanol, then ground in mesh extraction bags (Agdia Inc.) with $5 \mathrm{ml}$ of potassium phosphate buffer. The supernatant was serially diluted and a $0.1-\mathrm{ml}$ aliquot of each diluted sample was plated onto NBY agar medium supplemented with chloramphenicol $(10 \mu \mathrm{g} / \mathrm{ml})$. For root samples, serial dilutions were spread onto an improved $C$. michiganensis subsp. michiganensis semiselective medium, D2ANX (1). Colonies were checked for bioluminescence using the IVIS and counted on the fourth (on NBY) or seventh (on D2ANX) day after plating. The number of bacteria present in tomato tissue (CFU per gram) was calculated as the number of colonies $\times$ dilution factor $\times 3$ or $5 \mathrm{ml}$ per gram fresh weight of sample tissue.

The movement of the bioluminescent bacteria up and down the stem from the inoculated cotyledons was determined by stem tissue imprinting (16) using three of the tomato seedlings that were sampled for leaf isolation at each imaging time. The stem was cut every centimeter above, below, and including the cotyledon node using a sterilized scalpel, and the cut surface was imprinted on D2ANX medium in a square plate $(10$ by $10 \mathrm{~cm}$ 
with a $13-\mathrm{mm}$ grid). The colonies on the plates were imaged using the IVIS after 7 days of incubation at $28^{\circ} \mathrm{C}$. The experiment was repeated once.

Assessment of symptom development. Fifty seedlings were inoculated as described above and leaf wilting was monitored daily under low- and high-RH regimes. The percentage of symptomatic seedlings (wilt incidence) was recorded daily until 20 DPI and the area under disease progress curve (AUDPC) was calculated using the formula $\Sigma\left[\left(d_{\mathrm{i}+1}+d_{\mathrm{i}}\right) / 2\right]\left(t_{\mathrm{i}+1}-t_{\mathrm{i}}\right)$, where $d_{\mathrm{i}}$ and $d_{\mathrm{i}+1}$ are the wilt incidence at $i$ and $i+1$ DPI and $t_{\mathrm{i}}$ and $t_{i+1}$ are the days postinoculation. The experiment was conducted three times.

Data analysis. Bacterial population numbers in planta $(\mathrm{CFU}$ per gram) were log transformed and the AUDPC was square root transformed. Data for leaf, stem, and root bacterial populations, and root fresh weight from two experimental runs, were pooled based on results from Levene's tests of equal variance, which were not statistically significant for any of the measured responses $(P>0.05)$. Comparison of fresh weight of roots and bacterial populations in leaves, stems, and roots was done using SAS (version 9.1; SAS Institute, Cary, NC) with a MIXED model, and means were separated by a least significant difference test at the 5\% level of significance. Regression analysis of light intensity versus bacterial population in stems was performed by using the Minitab/Regression/Fitted Line plot.

\section{RESULTS}

Bioluminescent $C$. michiganensis subsp. michiganensis colonization of tomato seedlings. Individual images of bioluminescent $C$. michiganensis subsp. michiganensis colonization of tomato seedlings under high and low RH are presented in Figure 1. The inoculum load on the cotyledon petioles was log $3.8 \pm 0.4$ CFU/wound after clipping cotyledons with $C$. michiganensis subsp. michiganensis-contaminated dissecting scissors. At 5 DPI, strong luminescence was apparent in the cotyledon petioles, indicating rapid multiplication of BL-Cmm 17. Populations of $\log 7.3 \pm$ 0.2 and $7.4 \pm 0.2$ detected in cotyledon petioles under low and high $\mathrm{RH}$, respectively, were not significantly different $(P>0.05)$. The first and second true leaves were infected with low titers of bacteria under low RH (Table 1). In contrast, four leaves were infected under high RH. However, the titers were too low to be detected by the imaging system. The $C$. michiganensis subsp. michiganensis population in leaf 3 was significantly lower under low RH than under high RH. Luminescence signals observed in stems at this time point indicated the initiation of stem colonization.

Luminescence in stems was observed at 10 DPI in seedlings maintained in both low and high $\mathrm{RH}$. The bacteria multiplied in the stem and moved toward both roots and shoots. The petioles of cotyledons wilted and fell from the seedlings prior to imaging at 10 DPI. A few bioluminescent signals were detected in the first leaf of the seedling under low RH. The petioles of first and second leaves of the seedling under high $\mathrm{RH}$ were luminescent (Fig. 1). Isolation of bacteria from leaves showed that all leaves were infected in seedlings under both low and high RH without significant differences in C. michiganensis subsp. michiganensis populations between humidity regimes (Table 1). However, the population size of $C$. michiganensis subsp. michiganensis was larger by at least three orders of magnitude in all leaves at 10 compared with 5 DPI.

At 15 DPI, bioluminescence was observed in lower leaves of tomato seedlings under low $\mathrm{RH}$ and in all leaves of seedlings under high RH. The first true leaf of seedlings maintained under high RH wilted slightly within $15 \mathrm{DPI}$; lower leaves of seedlings under both low and high humidity were completely wilted by 20 DPI. Significantly larger $C$. michiganensis subsp. michiganensis populations were detected in leaves 1, 5, and 6 at 15 DPI and 2, 3, and 6 at 20 DPI from seedlings maintained under high RH than from those under low RH (Table 1). Luminescence was observed throughout the entire seedling under both RH regimes at 20 DPI. Higher amounts of luminescence were emitted from the nodes in stems than from the internodes. In individual compound leaves, the strongest signals appeared in the petiole nearest the main stem at 20 DPI (Fig. 2). Additionally, C. michiganensis subsp. michiganensis moved along the rachis of tomato leaves. No luminescence was observed or bioluminescent bacteria isolated from the control seedlings at any of the four sampling times.

Monitoring bioluminescent $C$. michiganensis subsp. michiganensis movement in stems by tissue imprinting. A representative luminescence image of detection of BL-Cmm17 movement in stems by tissue imprinting on semiselective medium is presented in Supplementary Figure S1. Bioluminescent C. michiganensis subsp. michiganensis was frequently detected up to 2 and $3 \mathrm{~cm}$ above the inoculated cotyledons in seedlings at 5 DPI grown under low and high RH, respectively. However, C. michiganensis subsp. michiganensis was detected at high frequency $4 \mathrm{~cm}$ below the cotyledons in seedlings under both humidity regimes (Table 2). At 10 DPI, C. michiganensis subsp. michiganensis was detected up to 3 and $4 \mathrm{~cm}$ above the cotyledons in more than half of the seedlings sampled under low and high $\mathrm{RH}$, respectively. At 15 and 20 DPI, C. michiganensis subsp. michiganensis was present in all stem sections. Additionally, bacteria were detected in the top of the stem but not 1 or $2 \mathrm{~cm}$ lower in the stem in four seedlings under high and low RH 10 and 20 DPI.

Bioluminescent $C$. michiganensis subsp. michiganensis colonization of roots. Tomato roots were also colonized when seedlings were inoculated by clipping the cotyledons (Fig. 3). Very weak signals were found at the juncture of roots and stem 5 DPI; however, signals were apparent in the taproots 10 DPI. Luminescent signals continued to increase in roots 15 DPI and strong signals in lateral roots were observed 20 DPI. Bacterial

TABLE 1. Populations of Clavibacter michiganensis subsp. michiganensis bioluminescent strain BL-Cmm17 in tomato compound leaves under regimes of low $(45 \%)$ and high $(83 \%)$ relative humidity $(\mathrm{RH})$

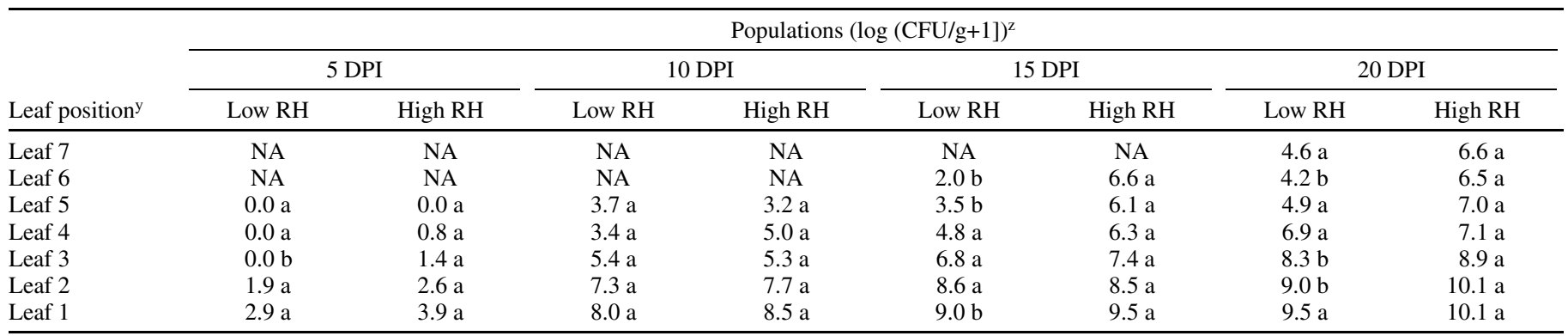

${ }^{y}$ Leaf position is listed from the newest (leaf 7) to oldest (leaf 1) leaf.

${ }^{\mathrm{z}}$ Bacterial populations were compared at the same leaf position between low and high RH at 5, 10, 15, and 20 days postinoculation (DPI). Means $(n=6)$ in a row at each time point and leaf position followed by the same letter were not significantly different at $P<0.05$. NA = not applicable because the leaf had not yet been produced at the indicated sampling time. 
populations in roots 5 DPI reached $\log 5.3 \pm 0.3$ and $5.9 \pm 0.5$ CFU/g under low and high $\mathrm{RH}$, respectively (Fig. 4A). The $C$. michiganensis subsp. michiganensis populations reached $>7 \operatorname{logs}$ $\mathrm{CFU} / \mathrm{g}$ at $10 \mathrm{DPI}$. There were no significant differences in $C$. michiganensis subsp. michiganensis populations in roots of seedlings under low and high RH.

The fresh weight of roots from inoculated seedlings maintained under low and high RH was significantly reduced 15 and 20 DPI compared with the water-inoculated control under high RH (Fig. 4B). No significant differences were observed in root weight of noninoculated control seedlings under low and high RH (data not shown).

Relationship between bioluminescence and bacterial populations in planta. Regression analysis showed a significant positive linear relationship between bioluminescence intensity and bacterial population in stems $(P<0.0001, r=0.94)$, indicating that stronger light signals corresponded with higher bacterial populations in planta (Fig. 5).

Wilting development under low- and high-RH regimes. Plant wilting incidence was significantly lower in seedlings under low RH than high RH 11 and 14 to 18 DPI $(P<0.05)$ but the difference was not significant 19 and 20 DPI (Fig. 6). The AUDPC was significantly higher under high RH $($ AUDPC $=341)$ than under low RH (AUDPC = 270). No wilting was observed in the water-inoculated control seedlings.

\section{DISCUSSION}

Bioluminescence imaging and bacterial isolations from inoculated tomato seedlings incubated under low- and high-RH regimes
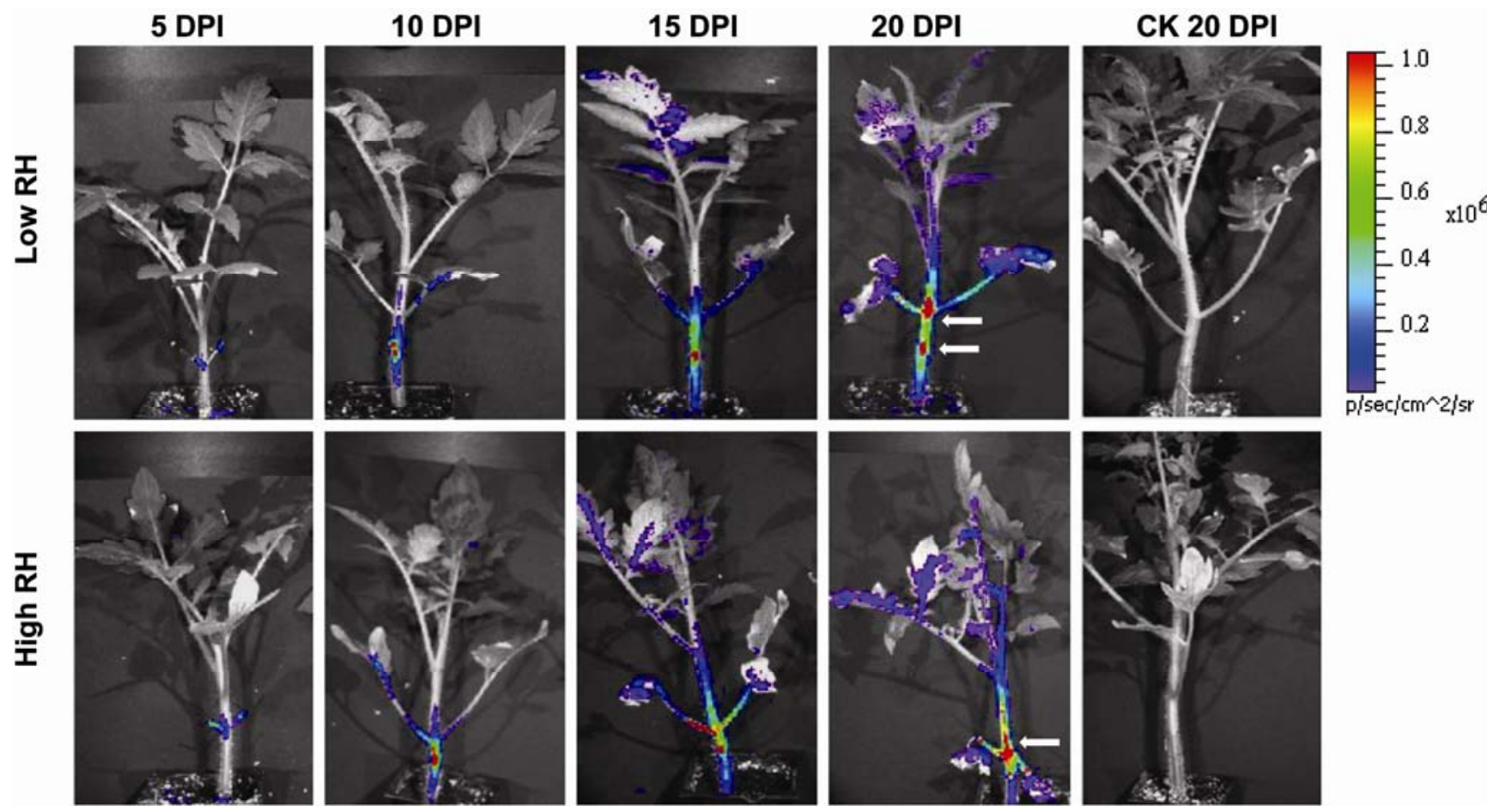

Fig. 1. Bioluminescence imaging of Clavibacter michiganensis subsp. michiganensis strain BL-Cmm17 colonization of tomato seedlings under regimes of low $(45 \%)$ and high $(83 \%)$ relative humidity $(\mathrm{RH})$ in real time. Images of the same seedlings were acquired 5, 10, 15, and 20 days postinoculation (DPI) using an in vivo imaging system. Images of water-inoculated control seedlings (CK) acquired 20 DPI are shown. Upper images are of a seedling held under low RH and lower images are of a seedling held under high RH. Arrows point to the strong luminescence signals at nodes. The rainbow scale represents light intensity at $0.2 \times$ $10^{6} \mathrm{p} / \mathrm{s} / \mathrm{cm}^{2} / \mathrm{sr} / \mathrm{unit}$.
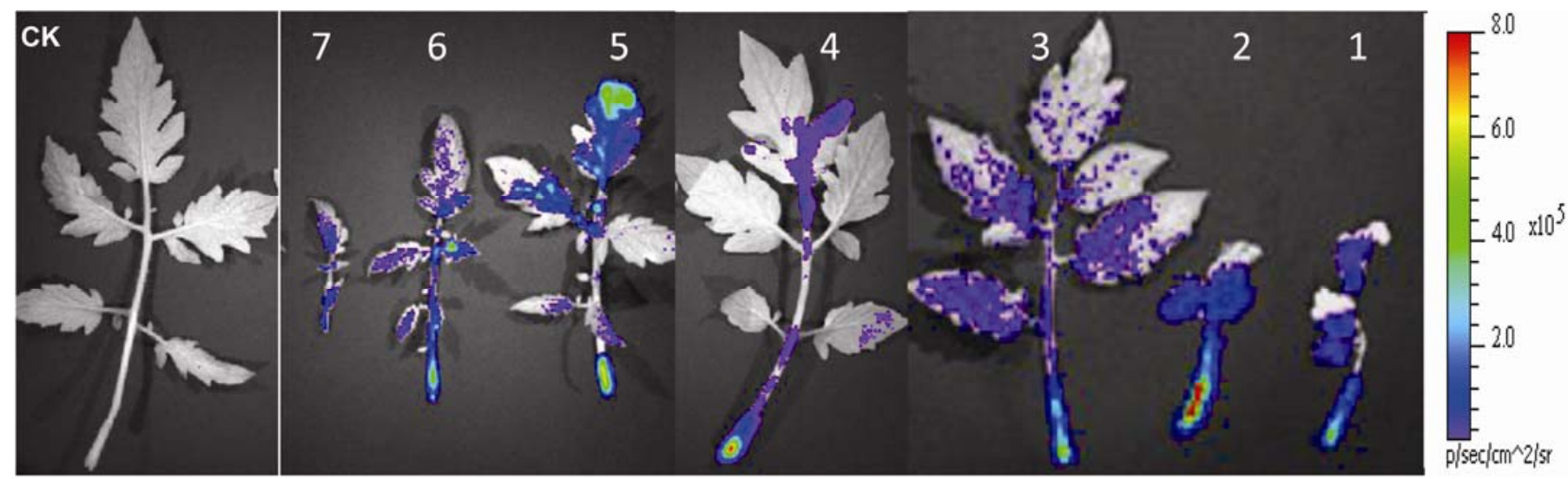

Fig. 2. Bioluminescence imaging of Clavibacter michiganensis subsp. michiganensis strain BL-Cmm17 colonization of tomato leaves from a tomato seedling under high relative humidity (83\%) 20 days postinoculation (DPI). Numbers at the top from left to right indicates the leaf position from the youngest (number 7) to the oldest leaf (number 1). Image of a leaf from a water-inoculated control seedling (CK) acquired 20 DPI is shown. Images of leaves 1 to 3 and 5 to 7 were taken on the adaxial surface; the images of leaf 4 and CK were taken on the abaxial surface. The rainbow scale represents light intensity at $2 \times 10^{5} \mathrm{p} / \mathrm{s} / \mathrm{cm}^{2} / \mathrm{sr} / \mathrm{unit}$. 
revealed that high environmental humidity accelerated symptom development by promoting the C. michiganensis subsp. michiganensis systemic infection process. To our knowledge, this is the first study in which $C$. michiganensis subsp. michiganensis colonization of tomato plants has been visualized in planta in real time. The bioluminescent strain BL-Cmm17, with lux genes encoding enzymes for light production, was detected in plants using a highly sensitive CCD camera, which allowed noninvasive moni- toring of this vascular pathogen in individual plants over a period of 20 DPI. Green fluorescent protein (GFP) is much more commonly used as a marker in the study of plant-pathogen interactions than bioluminescence. Previously, Chalupowicz et al. (5) constructed a GFP-labeled C. michiganensis subsp. michiganensis strain and used it to study $C$. michiganensis subsp. michiganensis colonization of the xylem, as well as C. michiganensis subsp. michiganensis epiphytic fitness and biofilm for-

TABLE 2. Detection of Clavibacter michiganensis subsp. michiganensis bioluminescent strain BL-Cmm17 in tomato stems under regimes of low (45\%) and high $(83 \%)$ relative humidity $(\mathrm{RH})$ by tissue imprinting

\begin{tabular}{|c|c|c|c|c|c|c|c|c|}
\hline \multirow[b]{3}{*}{ Distance from cotyledons $(\mathrm{cm})^{\mathrm{y}}$} & \multicolumn{8}{|c|}{ Detection $^{\mathrm{z}}$} \\
\hline & \multicolumn{2}{|c|}{$5 \mathrm{DPI}$} & \multicolumn{2}{|c|}{10 DPI } & \multicolumn{2}{|c|}{$15 \mathrm{DPI}$} & \multicolumn{2}{|c|}{20 DPI } \\
\hline & Low RH & High RH & Low RH & High RH & Low RH & High RH & Low RH & High RH \\
\hline \multicolumn{9}{|l|}{ Above cotyledon node } \\
\hline 7 & NA & NA & NA & NA & $2 / 5$ & $4 / 6$ & $4 / 6$ & $5 / 6$ \\
\hline 6 & NA & NA & $1 / 4$ & $2 / 4$ & $3 / 6$ & $4 / 6$ & $4 / 6$ & + \\
\hline 5 & - & - & $1 / 6$ & $2 / 6$ & + & + & + & + \\
\hline 4 & - & $1 / 6$ & $3 / 6$ & $4 / 6$ & + & + & + & + \\
\hline 3 & $1 / 6$ & $3 / 6$ & $4 / 6$ & $5 / 6$ & + & + & + & + \\
\hline 2 & $3 / 6$ & $4 / 6$ & + & + & + & + & + & + \\
\hline 1 & $5 / 6$ & + & + & + & + & + & + & + \\
\hline \multicolumn{9}{|l|}{ Cotyledon node } \\
\hline 0 & + & + & + & + & + & + & + & + \\
\hline \multicolumn{9}{|l|}{ Below cotyledon node } \\
\hline-1 & + & + & + & + & + & + & + & + \\
\hline-2 & + & + & + & + & + & + & + & + \\
\hline-3 & $5 / 6$ & + & + & + & + & + & + & + \\
\hline-4 & $4 / 5$ & $5 / 6$ & + & + & + & + & + & + \\
\hline
\end{tabular}

y Distance from inoculated cotyledons in stem.

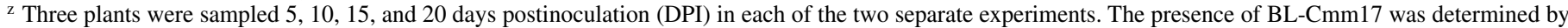
culturing on D2ANX semiselective medium and identified by luminescence imaging. NA = not applicable because the seedling had not reached that height at the indicated sampling time, $+=$ presence of BL-Cmm17 in all six samples $(6 / 6),-=$ no presence of BL-Cmm17 in all six samples $(0 / 6)$, and fraction $=$ number of samples with BL-Cmm17/total number of samples tested.

5 DPI
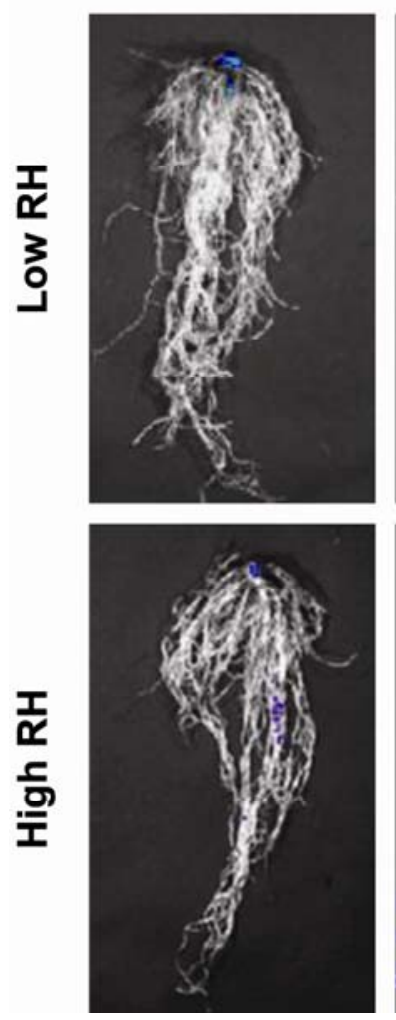

$10 \mathrm{DPI}$
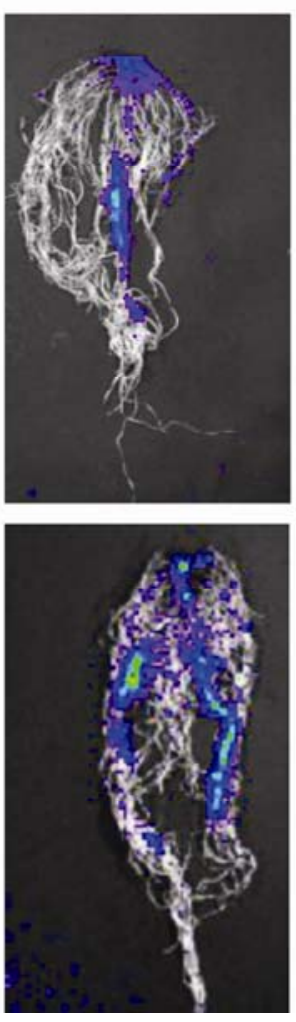

15 DPI
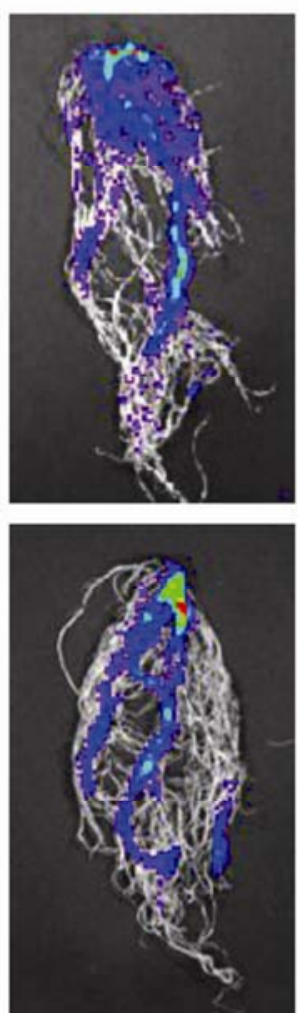

20 DPI
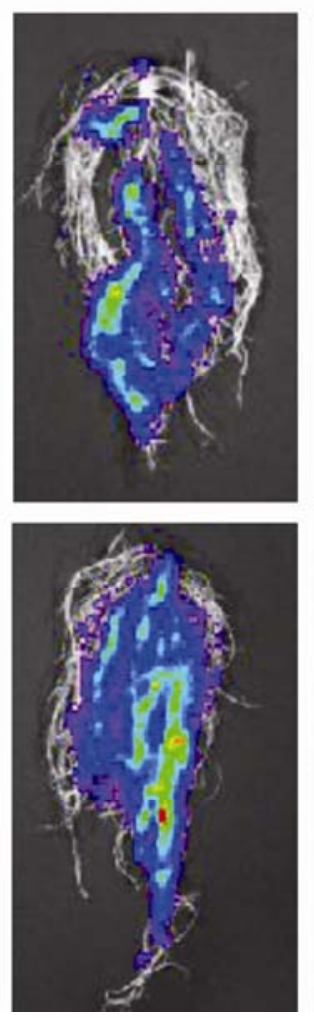

\section{CK 20DPI}
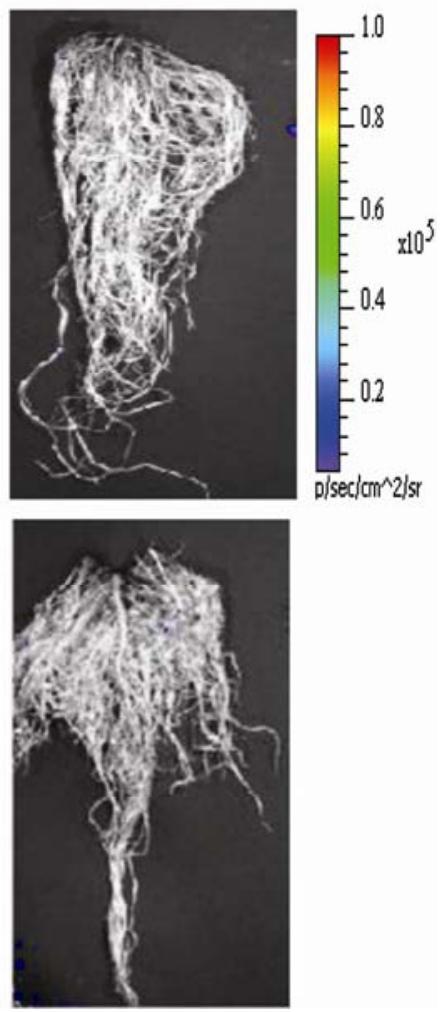

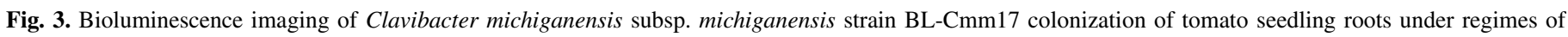

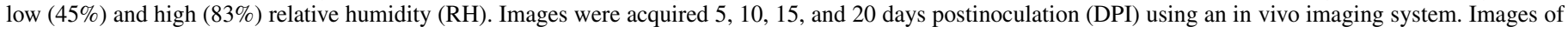

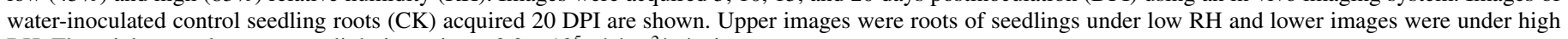
$\mathrm{RH}$. The rainbow scale represents light intensity at $0.2 \times 10^{5} \mathrm{p} / \mathrm{s} / \mathrm{cm}^{2} / \mathrm{sr} / \mathrm{unit}$. 
mation on leaves. However, the $g f p$ gene in this strain was carried on a plasmid that was not stable after 1 month in planta. Further, fluorescence imaging requires UV excitation light and dissection of plant tissues. In contrast, the chromosome insertion of luxoperon in $C$. michiganensis subsp. michiganensis strain BLCmm17 (38) was stable and bioluminescence imaging allowed visualization of bacteria in planta without tissue dissection or excitation. Therefore, bioluminescence imaging is a suitable approach for real-time, noninvasive evaluation of $C$. michiganensis subsp. michiganensis colonization and latent infection.

Most of the previous studies of bioluminescence imaging to monitor lux-marked bacterial infection in plant hosts involved exposure of the inoculated leaf, stem, or root to X-ray film $(9,11,13,22)$. Although the use of X-ray or photographic film is inexpensive, this indirect imaging technique is relatively less sensitive and more time consuming than digital imaging (32). Only a few studies have demonstrated luminescence directly in infected plants using low-light-detecting cameras $(4,32)$. This was done by taking two photos, one with light to show the plant tissue and another in the dark to detect the emitted light and locate the bioluminescent pathogen (4,32). The imaging system (IVIS; Xenogen Corporation) used in this study takes two images with a highly sensitive, thermoelectrically cooled $\left(-90^{\circ} \mathrm{C}\right) \mathrm{CCD}$ camera capable of detecting 100 photons $/ \mathrm{s} / \mathrm{cm}^{2} / \mathrm{sr}$. In addition, an overlay image of the object in light and luminescence in darkness is generated automatically by the Living Image software, and light intensity is represented by pseudocolor. The software enables quantitative analysis of light emission, which is very useful to correlate luminescence with the bacterial population in the host. The IVIS has been previously used to visualize bacterial and viral

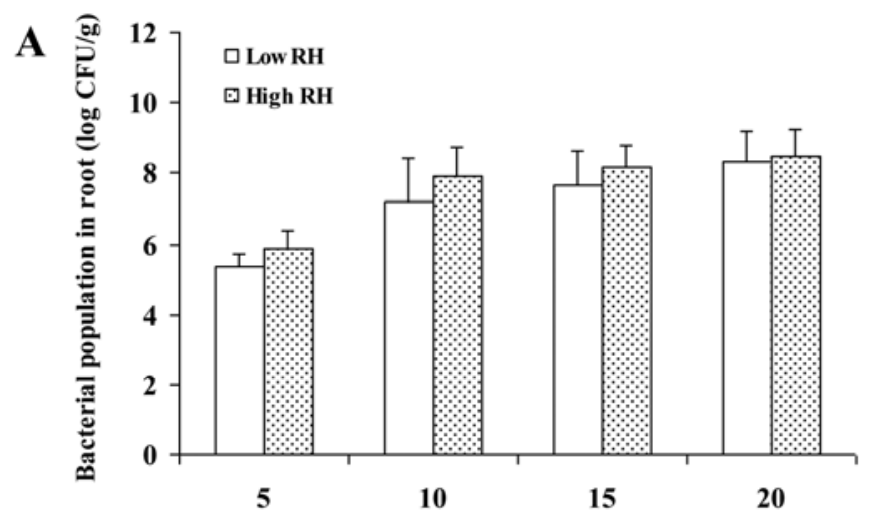

Days postinoculation (DPI)

B

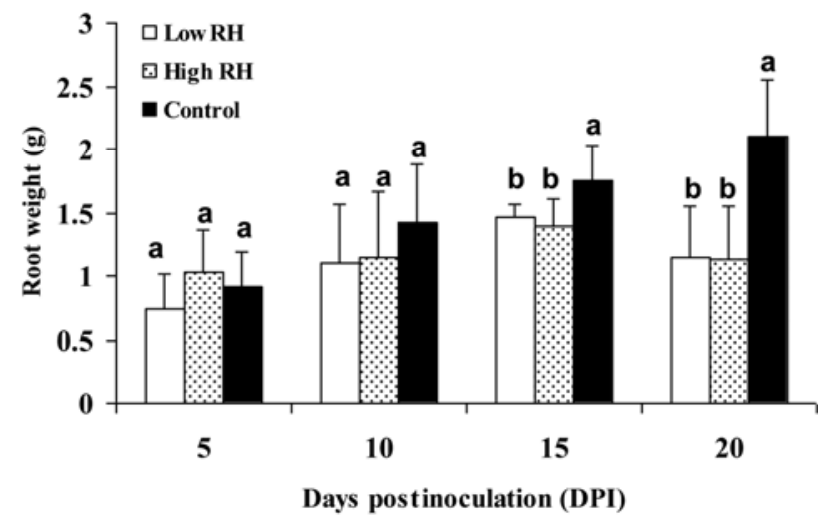

Fig. 4. Comparison of $\mathbf{A}$, populations of Clavibacter michiganensis subsp. michiganensis bioluminescent strain BL-Cmm17 recovered from roots and $\mathbf{B}$, fresh weight of roots under regimes of low (45\%) and high (83\%) relative humidity (RH). CK represents the root weight of the water-inoculated control under high RH. Each bar represents the mean $(n=6)$ bacterial populations ( $\log \mathrm{CFU} / \mathrm{g}$ ) or fresh weights (g) at each sampling time and vertical bars represent standard errors. infection and proliferation of tumor cells in mouse models $(24,28,31)$. Unlike mice, which emit very few background signals (20), plant phosphorescence can be detected by this sensitive equipment, making it difficult to differentiate BL-Cmm17 bioluminescence from background light emitted by the plant. Incubation in the dark as described in this article quenches the phosphorescence, which facilitates tracking of the bioluminescent bacterial movement in tomato plants in real-time.

Although it is recognized that C. michiganensis subsp. michiganensis is a good endophyte that colonizes the vascular tissue of tomato, little is known regarding systemic movement and translocation of this pathogen in seedlings. An early study in which inoculated tomato tissues were stained with safranin and fast green demonstrated that $C$. michiganensis subsp. michiganensis infects vascular elements of the leaf traces, moving into the main axis of the stem, and then moves extensively in spiral vessel elements of the primary xylem (30). Later microscopic observations, including a recent preliminary report, of both wildtype and GFP-labeled $C$. michiganensis subsp. michiganensis strains further demonstrated that $C$. michiganensis subsp. michi-

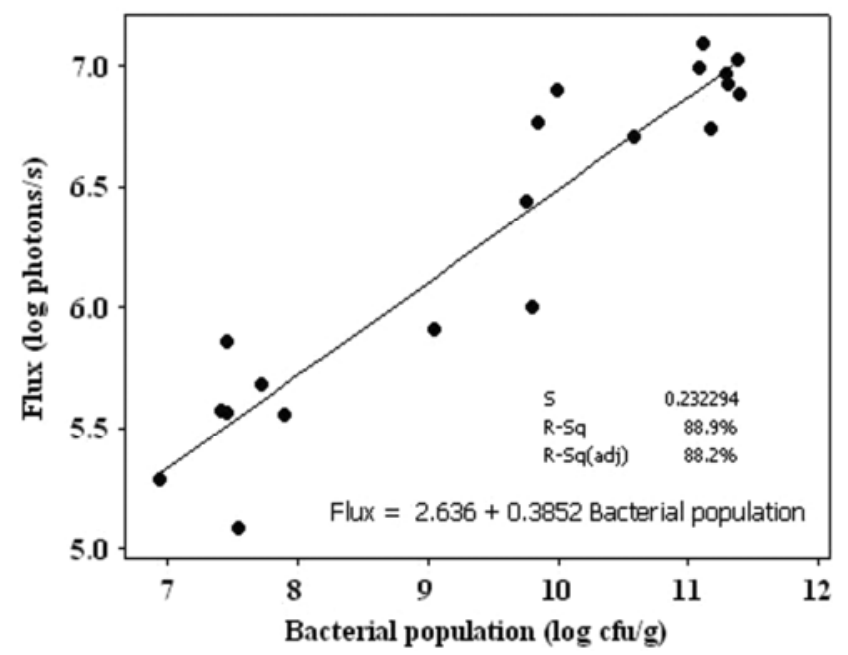

Fig. 5. Regression analysis of light intensity versus population of bioluminescent Clavibacter michiganensis subsp. michiganensis strain BL-Cmm17 recovered from tomato seedling stems. Data points were bacterial populations and light intensities from $1 \mathrm{~cm}$ above the cotyledons in stems $(n=20)$.

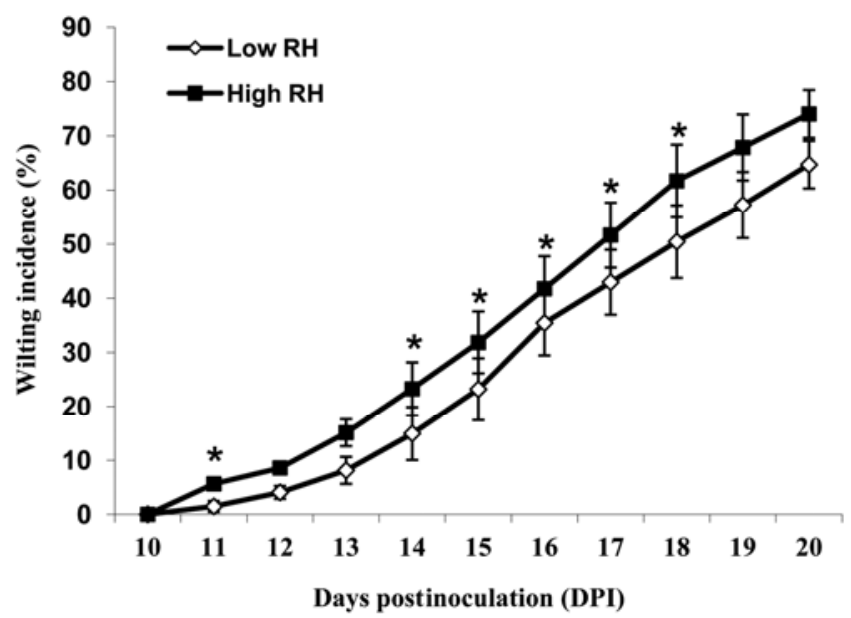

Fig. 6. Wilting progress curves of inoculated seedlings under regimes of low $(45 \%)$ and high $(83 \%)$ relative humidity $(\mathrm{RH})$. Data points were means of three replications with 50 inoculated seedlings and vertical bars represent standard errors. Asterisks $(*)$ indicate statistically significant differences $(P \leq$ 0.05 , by least significant difference test) in mean incidence of wilting between high and low RH. 
ganensis attaches to spiral rings in protoxylem vessels at an early stage of infection and then colonizes the whole-xylem vessels extensively at later stages of infection $(3,5)$. Pine and coworkers (30) also used the cotyledon petiole clip inoculation method and reported that they found $C$. michiganensis subsp. michiganensis up to $1.32 \mathrm{~cm}$ above and $3.25 \mathrm{~cm}$ below the inoculation point at 5 DPI. Our results are consistent with their observation that bacteria move more rapidly toward roots than shoots, although we found $C$. michiganensis subsp. michiganensis up to $3 \mathrm{~cm}$ (low $\mathrm{RH}$ ) or $4 \mathrm{~cm}$ (high $\mathrm{RH}$ ) above and $4 \mathrm{~cm}$ below the inoculation point in seedlings 5 DPI. Interestingly, we noticed the accumulation of C. michiganensis subsp. michiganensis in nodes, which might be due to a larger percentage of vascular tissue in this part of the plant than others, allowing for more extensive bacterial multiplication. Bacterial populations were high in roots at an early stage of infection, as well as in the newest leaf at late stages of infection. The rapid migration and accumulation of C. michiganensis subsp. michiganensis in systemically infected seedlings requires thorough sanitation during the grafting process to prevent spread of bacterial canker. In addition, when screening for $C$. michiganensis subsp. michiganensis latent infections in seedlings in the greenhouse, the stem nodes and roots may be preferred sampling sites to increase the chances of successful detection of the pathogen.

Bacterial canker symptom development is complex and disease severity is influenced by host age, nutrition level, environment, and inoculum concentration $(7,35)$. An early study of sprayinoculated tomato seedlings showed that high $\mathrm{RH}$ (87 to 97\%) was favorable for leaf symptom development under a range of temperatures $\left(15\right.$ to $\left.28^{\circ} \mathrm{C}\right)$ (2). In addition, high $\mathrm{RH}$ facilitated seed transmission of $C$. michiganensis subsp. michiganensis by increasing the percentage of diseased seedlings arising from artificially infected seed (36). In this study, we found that high humidity also accelerated wilting in young tomato seedlings infected by wounding.

The mechanism of $C$. michiganensis subsp. michiganensis movement in tomato xylem is not clearly understood. Bacteria in the genus Clavibacter have no flagella and are nonmotile (10). It is reasonable to propose that bacterial migration from root to shoot is facilitated by water transport in the xylem. However, we demonstrated downward translocation of $C$. michiganensis subsp. michiganensis in tomato stems under both $\mathrm{RH}$ regimes, demonstrating that $C$. michiganensis subsp. michiganensis can also move against the direction of the transpiration stream in the xylem. Microscopic observations have shown that $C$. michiganensis subsp. michiganensis degrades the walls of xylem vessels using extracellular enzymes, which leads to collapse of plant cells and creation of large intercellular spaces $(3,15,21,30)$. It appears that formation of bacterial pockets facilitates intercellular expansion (30). Xylella fastidiosa, which is xylem limited, migrates against the transpiration stream through a type IV pilus-driven twitching motility (25). Twitching motility is also found in the tomato wilt pathogen $R$. solanacearum and is required for full virulence (23). Twitching motility appears to be largely restricted to gram-negative bacteria, with the exception of the gram-positive bacterium Streptococcus sanguis (17). Though putative pilin genes are present in the $C$. michiganensis subsp. michiganensis genome (14), the role of pili in motility is unknown. Further studies on the translocation of $C$. michiganensis subsp. michiganensis in planta are needed to reveal the mechanisms of environmental influences on systemic $C$. michiganensis subsp. michiganensis colonization.

The intensity of light production by bioluminescent $C$. michiganensis subsp. michiganensis in infected tomato tissues was highly correlated with bacterial populations in planta. Because luciferase activity depends on the metabolic integrity of the cell, the amount of photons emitted correlates with biomass of living bacteria $(12,29)$. The sensitivity of the current system is $\approx 10^{7} \mathrm{CFU} / \mathrm{g}$ of fresh tissue, which is lower than reported in hostpathogen systems with lux-tagged gram-negative bacteria $(12,29)$. For example, bioluminescent Pseudomonas syringae was detected at $\approx 10^{4} \mathrm{CFU} / \mathrm{ml}$ of bean leaf extract or $10^{4} \mathrm{CFU} /$ leaf disc of Arabidopsis thaliana (12,29). In this case, light measurements by luminometry of inoculated leaf discs or ground tissue in buffer may have increased the detection limit of bioluminescent bacteria, or the lux genes are expressed more efficiently in gram-negative than gram-positive bacteria. Because the lux operon is low in GC $(<31 \%)$ content and originally from gram-negative $P$. luminescens, its inefficient expression in high-GC $(>70 \%)$, grampositive $C$. michiganensis subsp. michiganensis would not be surprising. Nevertheless, our study demonstrated the usefulness of bioluminescent $C$. michiganensis subsp. michiganensis in monitoring pathogenesis in real time. Future work to optimize expression of the lux genes in C. michiganensis subsp. michiganensis may improve the limit of detection. Microscopic observation of naturally bioluminescent bacterial cells or lux-labeled phytopathogenic bacteria in plant tissues has been shown using appropriate equipment $(19,34)$. Thus, future visualization of bioluminescent $C$. michiganensis subsp. michiganensis in plant cells at the microscopic level together with successive observation of pathogen growth and temporal spread in vivo will improve our understanding of $C$. michiganensis subsp. michiganensis-tomato interactions. Currently, there are no tomato varieties resistant to C. michiganensis subsp. michiganensis and bactericides are ineffective once the pathogen has entered the plant. The use of a bioluminescent $C$. michiganensis subsp. michiganensis strain coupled with a sensitive imaging system, as demonstrated in this study, may prove to be very useful in developing or screening disease management tools such as canker-resistant cultivars and effective bactericides.

\section{LITERATURE CITED}

1. Alvarez, A. M., Kaneshiro, W. S., and Vine, B. G. 2005. Diversity of Clavibacter michiganensis subsp. michiganensis populations in tomato seed: what is the significance? Acta Hortic. 695:205-213.

2. Basu, P. K. 1966. Conditions for symptomatologicial differentiation of bacterial canker, spot, and speck of tomato seedlings. Can. J. Plant. Sci. 46:525-530.

3. Carlton, W. M., Braun, E. J., and Gleason, M. L. 1998. Ingress of Clavibacter michiganensis subsp. michiganensis into tomato leaves through hydathodes. Phytopathology. 88:525-529.

4. Chabot, R., Antoun, H., Kloepper, J. W., and Beauchamp, C. J. 1996. Root colonization of maize and lettuce by bioluminescent Rhizobium leguminosarum biovar phaseoli. Appl. Environ. Microbiol. 62:2767-2772.

5. Chalupowicz, L., Dror, O., Cohen-Kandli, M., Eichenlaub, R., Zellermann, E., Gartemann, K., Sessa, G., Barash, I., and ManulisSasson, S. 2010. Cmm-tomato interactions: visualization during infection, biofilm formation and epiphytic fitness. (Abstr.) Phytopathology 100:S22

6. Chang, R. J., Ries, S. M., and Pataky, J. K. 1991. Dissemination of Clavibacter michiganensis subsp. michiganensis by practices used to produce tomato transplants. Phytopathology. 81:1276-1281.

7. Chang, R. J., Ries, S. M., and Pataky, J. K. 1992. Effects of temperature, plant age, inoculum concentration, and cultivar on the incubation period and severity of bacterial canker of tomato. Plant Dis. 76:1150-1155.

8. Cirvilleri, G., and Lindow, S. E. 1994. Differential expression of genes of Pseudomonas syringae on leaves and in culture evaluated with random genomic lux fusions. Mol. Ecol. 3:249-257.

9. Cirvilleri, G., Bella, P., and Catara, V. 2000. Luciferase genes as a marker for Pseudomonas corrugata. J. Plant Pathol. 82:237-241.

10. Davis, M. J., Gillespie, A. G., Jr., Vidaver, A. K., and Harris, R. W. 1984. Clavibacter: A new genus containing some phytopathogenic coryneform bacteria, including Clavibacter xyli subsp. xyli sp. nov., subsp. nov. and Clavibacter xyli subsp. cynodontis subsp. nov., pathogens that cause ratoon stunting disease of sugarcane and bermudagrass stunting disease. Int. J. Syst. Bacteriol. 34:107-117.

11. De Weger, L. A., Dunbar, P., Mahafee, W. F., Lugtenberg, J. J., and Sayler, G. S. 1991. Use of bioluminescent markers to detect Pseudomonas spp. in the rhizosphere. Appl. Environ. Microbiol. 57:3641-3644.

12. Fan, J., Crooks, C., and Lamb, C. 2008. High-throughput quantitative luminescence assay of the growth in planta of Pseudomonas syringae 
chromosomally tagged with Photorhabdus luminescens luxCDABE. Plant J. 53:393-399.

13. Fukui, R., Fukui, H., McElhaney, R., Nelson, S. C., and Alvarez, A. M. 1996. Relationship between symptom development and actual sites of infection in leaves of anthurium inoculated with a bioluminescent strain of Xanthomonas campestris pv. dieffenbachiae. Appl. Environ. Microbiol. 62:1021-1028.

14. Gartemann, K.-H., Abt, B., Bekel, T., Burger, A., Engemann, J., Flügel, M., Gaigalat, L., and Goesmann, A. 2008. The genome sequence of the tomato-pathogenic actinomycete Clavibacter michiganensis subsp. michiganensis NCPPB382 reveals a large island involved in pathogenicity. J. Bacteriol. 190:2138-2149.

15. Gartemann, K.-H., Kirchner, O., Engemann, J., Gräfen, I., Eichenlaub, R., and Burger, A. 2003. Clavibacter michiganensis subsp. michiganensis: first steps in the understanding of virulence of a gram-positive phytopathogenic bacterium. J. Biotechnol. 106:179-191.

16. Gitaitis, R. D., Beaver, R. W., and Voloudakis, A. E. 1991. Detection of Clavibacter michiganensis subsp. michiganensis in symptomless tomato transplants. Plant Dis. 75:834-838.

17. Henriksen S. D., and Henrichsen, J. 1975. Twitching motility and possession of polar fimbriae in spreading Streptococcus sanguis isolates from the human throat. Acta Pathol. Microbiol. Scand. B 83:133-140.

18. Hikichi, Y., Nakazawa-Nasu, Y., Kitanosono, S., Suzuki, K., and Okuno, T. 1999. The behavior of lux-marked Ralstonia solanacearum in grafted tomato cultivars resistant or susceptible to bacterial wilt. Ann. Phytopathol. Soc. Jpn. 65:597-603.

19. Hikichi, Y., Suzuki, K., Toyoda, K., Horikoshi, M, Hirooka, T., and Okuno., T. 1998. Successive observation of growth and movement of genetically lux-marked Pseudomonas cichorii and the response of host tissue in the same lettuce leaf. Ann. Phytopathol. Soc. Jpn. 64:519-525.

20. Hutchens, M., and Luker, G. D. 2007. Applications of bioluminescence imaging to the study of infectious diseases. Cell Microbiol. 9:2315-2322.

21. Jahr, H., Bahro, R., Burger, A., Ahlemeyer, J., and Eichenlaub, R. 1999. Interactions between Clavibacter michiganensis and its host plants. Environ. Microbiol. 1:113-118.

22. Kamoun, S., and Kado, C. I. 1990. A plant-inducible gene of Xanthomonas campestris pv. campestris encodes an exocellular component required for growth in the host and hypersensitivity on nonhosts. J. Bacteriol. 172:5165-5172.

23. Liu, H. L., Kang, Y. W., Genin, S., Schell, M. A., and Denny, T. P. 2001. Twitching motility of Ralstonia solanacearum requires a type IV pilus system. Microbiology 147:3215-3229.

24. Luker, G., Bardill, J., Prior, J., Pica, C., Piwnica-Worms, D., and Leib, D.
2002. Noninvasive bioluminescence imaging of herpes simplex virus type 1 infection and therapy in living mice. J. Virol. 76:12149-12161.

25. Meng, Y., Li, Y., Galvani, C. D., Hao, G., Turner, J. N., Burr, T. J., and Hoch, H. C. 2005. Upstream migration of Xylella fastidiosa via pilusdriven twitching motility. J. Bacteriol. 187:5560-5567.

26. Miller, S. A., Rowe, R. C., and Riedel, R. M. 1996. Bacterial spot, speck, and canker of tomatoes. Ohio State Univ. Ext. HYG-3120-96.

27. Park, Y. H., Suzuki, K. Yim, D. G., Lee, K. C., Yoon, J., Kim, S., Kho, Y. H., Goodfellow, M., and Komagata, K. 1993. Suprageneric classification of peptidoglycan group B actinomycetes by sequencing of $5 \mathrm{~s}$ ribosomal RNA. Antonie Leeuwenhoek 64:307-313.

28. Paroo, Z., Bollinger, R., Braasch, D. A., Richer, E., Corey, D. R., Antich, P. P., and Mason, R. P. 2004. Validating bioluminescence imaging as a high-throughput, quantitative modality for assessing tumor burden. Mol. Imag. 3:117-124.

29. Paynter, C. D., Salisbury, V. C., Arnold, D. L., and Jackson, R. W. 2006. The use of bioluminescence for monitoring in planta growth dynamics of a Pseudomonas syringae plant pathogen. Eur. J. Plant Pathol. 115:363-366.

30. Pine, T. S., Grogan, R. G., and Hewitt, W. B. 1954. Pathological anatomy of bacterial canker of young tomato plants. Phytopathology 45:267-271.

31. Rajashekara, G., Glover, D. A., Krepps, M., and Splitter, G. A. 2005. Temporal analysis of pathogenic events in virulent and avirulent Brucella melitensis infections. Cell. Microbiol. 7:1459-1473.

32. Shaw, J. J., Dane, F., Geiger, D., and Kloepper, J. W. 1992. Use of bioluminescence for detection of genetically engineered microorganisms released into the environment. Appl. Environ. Microbiol. 58:267-273.

33. Shirakawa, T., Sasaki, T., and Ozaki, K. 1991. Ecology and control of tomato bacterial canker and detection methods of its pathogen. Jpn. Agric. Res. Q. 25:27-32.

34. Sternberg, C., Eberl, L., Poulsen, L. K., and Molin, S. 1997. Detection of bioluminescence from individual bacterial cells: A comparison of two different low-light imaging systems. J. Biolumin. Chemilumin. 12:7-13.

35. Strider, D. L. 1969. Bacterial canker of tomato, a literature review and bibliography. N. C. Agric. Exp. Stn. Tech. Bull. 193.

36. Tsiantos, J. 1987. Transmission of bacterium Corynebacterium michiganense pv. michiganense by seeds. J. Phytopathol. 119:142-146.

37. Vidaver, A. K. 1967. Synthetic and complex media for the rapid detection of fluorescence of phytopathogenic pseudomonads: Effect of the carbon source. Appl. Microbiol. 15:1523-1524.

38. Xu, X., Miller, S. A., Baysal-Gurel, F., Gartemann, K.-H., Eichenlaub, R., and Rajashekara, G. 2010. Bioluminescence imaging of Clavibacter michiganensis subsp. michiganensis infection in tomato seeds and plants. Appl. Environ. Microbiol. 76:3978-3988. 